\title{
BMJ Open Cross-sectional study on parental pro-drinking practices and adolescent alcohol drinking in Hong Kong
}

\author{
Wing Man Au, ${ }^{1}$ Sai Yin Ho, ${ }^{1}$ Man Ping Wang, ${ }^{2}$ Wing Sze Lo, ${ }^{1}$ Sze Pui Pamela Tin, ${ }^{1}$ \\ Rong Huang, ${ }^{1}$ Tai Hing Lam ${ }^{1}$
}

To cite: Au WM, Ho SY, Wang MP, et al. Crosssectional study on parental pro-drinking practices and adolescent alcohol drinking in Hong Kong. BMJ Open 2016;6:e009804.

doi:10.1136/bmjopen-2015009804

- Prepublication history for this paper is available online. To view these files please visit the journal online (http://dx.doi.org/10.1136/ bmjopen-2015-009804).

Received 27 August 2015 Accepted 14 January 2016

CrossMark

\begin{abstract}
${ }^{1}$ School of Public Health, The University of Hong Kong, Hong Kong, Hong Kong

${ }^{2}$ School of Nursing, The University of Hong Kong, Hong Kong, Hong Kong
\end{abstract}

Correspondence to Dr Sai Yin Ho; syho@hku.hk

\section{ABSTRACT}

Objectives: To investigate the association between parental pro-drinking practices (PPDPs) and alcohol drinking in Hong Kong Chinese adolescents.

Design: A cross-sectional study.

Setting: 4 randomly selected secondary schools in Hong Kong.

Participants: 1738 students (mean age 14.6 years \pm 2.0 , boys $67.8 \%$ ).

Main outcome measures: Drinking status, drinking intention and exposure to 9 PPDPs (eg, seeing parents drunk, helping parents buy alcohol, encouraged to drink by parents) were reported by students. Logistic regression was used to compute adjusted ORs (AORs) of drinking and intention to drink by each PPDP and the number of PPDPs $(0,1-2,3-4,5$ or above), adjusting for sociodemographic characteristics, parental drinking and school clustering.

Results: Nearly half $(48.6 \%)$ of the students were ever-drinkers, $16.2 \%$ drank monthly (at least once per month) and $40.3 \%$ intended to drink in the next 12 months. Most PPDPs were significantly associated with ever drinking (AORs 1.40-6.20), monthly drinking (AORs 1.12-8.20) and intention to drink (AORs 1.405.02). Both ever and monthly drinking were most strongly associated with parental training of drinking capacity (ability to drink more without getting drunk) with AORs of 6.20 and 8.20 (both $p<0.001$ ), respectively. Adolescent drinking intention was most strongly associated with parental encouragement of drinking and training of drinking capacity with AORs of 3.19 and 5.02 (both $p<0.001$ ), respectively.

Conclusions: Exposure to PPDPs was associated with ever drinking, monthly drinking and drinking intention in Hong Kong Chinese adolescents. More studies, especially prospective studies, should be conducted to confirm these results, followed by interventional studies.

\section{INTRODUCTION}

Alcohol kills 3.3 million people per year worldwide and causes serious physical and psychosocial health consequences in adolescents. $^{1-3}$ Yet drinking is prevalent both in adults and in adolescents. In the USA, 66\% of grade 9-12 students had ever consumed

\section{Strengths and limitations of this study}

- This was the first study to examine a comprehensive list of parental pro-drinking practices.

- This study found novel associations between parental pro-drinking practices and adolescent alcohol drinking in Hong Kong, where drinking prevalence is relatively low.

- Self-reported data were used and causality cannot be inferred by the present cross-sectional study.

alcohol and $35 \%$ had consumed alcohol in the past 30 days. ${ }^{4}$

Parents have both antidrinking and prodrinking influences on adolescents. While parental monitoring and rule setting have been found to be protective, ${ }^{5}{ }^{6}$ parental drinking consistently predicted adolescent drinking..$^{7-9}$ In addition, parental approval of alcohol drinking has been associated with a greater risk of adolescent drinking in Western countries. ${ }^{10-12}$ In Australia, one-third of students aged 12-17 years had consumed alcohol provided by their parents and $64 \%$ of these students drank with parents. ${ }^{13}$ Parents popularly believe that introducing alcohol to young adolescents increases their resistance to peer influence on drinking and protects them from alcohol-related problems in adulthood, ${ }^{14}$ but results have been conflicting. A cross-sectional study conducted among Australian adolescents indicated that parental provision of adolescents' first alcohol drink was negatively associated with heavy episodic drinking. ${ }^{15}$ However, other studies showed that parental supply of alcohol was associated with alcohol use, intention to drink ${ }^{16} 17$ and even risky drinking $^{18}$ in young adolescents. Another study showed that parental approval of drinking by actively providing alcohol, drinking together, or refraining from disciplining adolescents caught drinking was associated with increased use of alcohol among adolescents. ${ }^{19}$ 
Apart from these explicit practices, parents might also unknowingly encourage adolescent drinking through various subtle ways, but reports on this are rare. In a recent study, fetching and pouring alcohol for adults were linked to alcohol sipping in adolescents. ${ }^{20}$ To the best of our knowledge, no studies have investigated the relation between adolescent drinking and a comprehensive list of parental pro-drinking practices (PPDPs). On the basis of telephone interviews with parents and adolescents and anecdotal reports, we have identified nine PPDPs in Hong Kong and shown that they increased dramatically with the number of parents who drank alcohol in the past 30 days(none/either/both). ${ }^{21}$ We also found that PPDPs were associated with higher socioeconomic status, and that girls were more likely to report parental training of drinking capacity (ability to drink more without getting drunk). ${ }^{22}$ Although the 30-day drinking prevalence of $18 \%$ among Hong Kong adolescents is relatively low compared with that among their Western counterparts, ${ }^{23}$ drinking has become increasingly socially acceptable in Hong Kong since 2008 when the beer and wine tax was waived to boost alcohol trade. ${ }^{24}$ The present study aims to investigate how PPDPs associate with alcohol drinking and the intention to drink among Hong Kong Chinese adolescents.

\section{METHODS}

\section{Participants and procedures}

In 2012, a total of 2200 students from four randomly selected local secondary schools (2 coeducational and 2 boys' schools from different districts in Hong Kong) completed a survey on alcohol use. Details of the survey and consent procedures have been reported elsewhere. ${ }^{21}$

The response rate was $50 \%$ at the school level $(8$ schools were invited in order to successfully recruit 4 schools) and $87.5 \%$ at the individual student level. After excluding students who responded to less than half of the survey items $(0.4 \%)$ or did not provide data on age $(1.8 \%)$, sex $(0.8 \%)$, PPDPs $(2.9 \%)$, individual drinking status $(0.4 \%)$, individual drinking intention $(0.8 \%)$ or parental drinking status $(14.2 \%), 1738(78.8 \%)$ students (mean age 14.6 years \pm 2.0 , boys $67.8 \%$ ) were available for analysis. Participants included and excluded for analysis had similar sociodemographic characteristics, such as age, sex and highest parental education level with small Cohen's w, that ranged from 0.04 to 0.18 , indicating minimal differences between the two groups.

\section{Measures}

Parental pro-drinking practices

PPDPs were categorised into four groups: (1) saw parents (a) drink and (b) drunk; (2) heard parents mentioning (a) the benefits of drinking and (b) that certain alcohol tastes good; (3) helped parents (a) buy alcohol, (b) open a bottle of alcohol and (c) pour alcohol and (4) parental actions that (a) encouraged me to drink and (b) trained my drinking capacity (ability to drink more without getting drunk). Students were asked whether they had come across the above situations and to choose each that was applicable to them. The PPDPs identified by each student were analysed as (A) individual practices and (B) the total number of practices $(0,1-2,3-4,5$ or above)

\section{Adolescent alcohol drinking and intention to drink}

The frequency of alcohol drinking was assessed using the question 'How often do you drink alcohol?' with nine response options from 'I don't drink', ' $\leq 1$ day/ year', '<1 day/month', '1 day/month', '2-3 days/month', ' 1 day/week', '2-3 days/week', '4-6 days/week' to 'daily'. Ever drinking referred to $\leq 1$ day/year or more frequent drinking. Monthly drinking was defined as 1 day/month or more frequent drinking. Drinking intention was assessed using the question 'Will you drink in the next 12 months?', with the response options 'definitely not', 'probably not', 'probably yes' or 'definitely yes'. Participants who chose 'definitely yes' or 'probably yes' were considered to have had an intention to drink.

\section{Covariates}

Covariates considered in analyses included age, sex, place of birth (Hong Kong or outside Hong Kong including Mainland China, Macau, Taiwan or others), family structure (parents are together or parents are divorced/separated/deceased/others), highest parental education level (primary or below, secondary or tertiary) and perceived family affluence (low, medium or high).

Parental drinking status was also considered a covariate and assessed using the question 'How often did your father/mother drink alcohol in the past 30 days?' separately for each parent. Each question had five response options: 'never' (classified as non-drinkers), 'seldom', 'sometimes', 'frequently' (classified as drinkers) or 'unknown'. Parental drinking status was subsequently classified as 'none', 'either' or 'both'. Consistent with our previous report, ${ }^{21}$ participants with unknown drinking status for both parents were excluded from the analysis; when the drinking status of one parent was unknown, parental drinking status was defined as 'none' if the other parent was a non-drinker, and 'either' if the other parent was a drinker.

\section{Statistical analysis}

Logistic regression using PPDPs as the independent variable yielded adjusted ORs (AORs) and 95\% CIs for ever drinking, monthly drinking and drinking intention. In model 1, each PPDP was analysed as a binary variable (present vs absent), and in model 2 the total number of PPDPs $(0,1-2,3-4,5$ or above) was analysed. Models were adjusted for the aforementioned covariates and for school clustering. School clustering was adjusted using the command 'robust clust (school variable)' in STATA V.10.1 


\section{RESULTS}

Most students were from intact families $(81.7 \%)$, born in Hong Kong $(74.8 \%)$, had parents with secondary or tertiary level education $(69.7 \%)$ and perceived family affluence as medium or high $(73.1 \%)$. More than half of the fathers $(57.5 \%)$ and one-third (36.1) of the mothers were ever-drinkers, although few drank frequently (12.0\% fathers and $2.5 \%$ mothers). Nearly half $(47.1 \%)$ of the students had ever drunk alcohol and $40.3 \%$ had an intention to drink. Details of student sociodemographics have been reported elsewhere. ${ }^{21}$

Seeing parents drink was the most common PPDP $(50.3 \%)$, followed by opening bottles of alcohol $(23.4 \%)$, pouring alcohol (22.9\%), hearing that alcohol tastes good (22.4\%), seeing parents drunk (19.5\%), buying alcohol $(18.9 \%)$, hearing benefits of drinking $(8.7 \%)$, being encouraged to drink $(8.3 \%)$, and training of drinking capacity $(5.5 \%)$.

Each PPDP was significantly associated with ever drinking and monthly drinking except for one association (between monthly drinking and seeing parents drink) (table 1). Adolescent monthly drinking was most strongly associated with the drinking capacity training (AOR 8.2), followed by pouring alcohol (3.03), being encouraged to drink (2.97), opening bottles of alcohol (2.63), hearing that alcohol tastes good (2.32), hearing about the benefits of drinking (2.23), buying alcohol (2.17) and seeing parents drunk (1.84). An increasing number of PPDPs was associated with monthly drinking in a dose-response fashion with the largest AOR of 6.22 for five or more PPDPs ( $p$ for trend $<0.001$ ). The results of individual PPDPs for ever drinking were similar, although the magnitude of associations was generally not as strong compared with monthly drinking.

Similarly, all PPDPs were associated with drinking intention (table 2): being encouraged to drink (AOR 3.19), drinking capacity training (5.02), pouring alcohol (2.15), hearing benefits of drinking (2.21), opening bottles of alcohol (2.02), seeing parents drink (1.40), hearing that alcohol tastes good (1.76), seeing parents drunk (1.57) and buying alcohol (1.81). Compared with the unexposed, students experiencing 1-2, 3-4 and 5 or above PPDPs were associated with having an intention to drink, with AORs of 1.19, 2.47and 4.32, respectively ( $\mathrm{p}$ for trend $<0.001$ ).

\section{DISCUSSION}

Exposure to PPDPs was associated with increased odds of both ever and monthly drinking in adolescents. According to the Social Learning Theory, adolescents may pick up drinking behaviour by learning from their

Table 1 Associations of PPDP with adolescent drinking

\begin{tabular}{|c|c|c|c|c|c|c|}
\hline & \multicolumn{3}{|c|}{ Ever drinking } & \multicolumn{3}{|c|}{ Monthly drinking } \\
\hline & $\begin{array}{l}\text { Per cent } \\
\text { when } \\
\text { PPDP } \\
\text { absent }\end{array}$ & $\begin{array}{l}\text { Per cent } \\
\text { when } \\
\text { PPDP } \\
\text { present }\end{array}$ & AOR (95\% Cl)† & $\begin{array}{l}\text { Per cent } \\
\text { when } \\
\text { PPDP } \\
\text { absent }\end{array}$ & $\begin{array}{l}\text { Per cent } \\
\text { when } \\
\text { PPDP } \\
\text { present }\end{array}$ & AOR $(95 \% \mathrm{Cl}) \dagger$ \\
\hline \multicolumn{7}{|l|}{ Parents were seen } \\
\hline Drinking & 41.7 & 55.3 & $1.50(1.22 \text { to } 1.84)^{\star \star \star}$ & 15.6 & 16.7 & $1.12(0.81$ to 1.55$)$ \\
\hline Drunk & 45.1 & 61.7 & $1.40(1.09 \text { to } 1.80)^{\star *}$ & 14.0 & 24.9 & $1.84(1.28 \text { to } 2.62)^{\star \star}$ \\
\hline \multicolumn{7}{|c|}{ Parents were heard mentioning } \\
\hline Benefits of drinking & 46.2 & 69.8 & $1.94(1.35 \text { to } 2.80)^{\star \star \star}$ & 15.2 & 25.1 & $2.23(1.36 \text { to } 3.67)^{\star \star}$ \\
\hline Alcohol tastes good & 42.3 & 67.2 & $2.05(1.60 \text { to } 2.63)^{\star \star \star}$ & 13.8 & 23.5 & $2.32(1.63 \text { to } 3.32)^{\star \star \star}$ \\
\hline \multicolumn{7}{|l|}{ Parents being helped } \\
\hline Buy alcohol & 44.8 & 63.7 & $1.67(1.29 \text { to } 2.17)^{\star \star \star}$ & 14.0 & 25.0 & $2.17(1.51 \text { to } 3.11)^{\star \star \star}$ \\
\hline Open bottle & 42.9 & 67.1 & $2.36(1.85 \text { to } 3.01)^{\star \star \star}$ & 13.2 & 26.3 & $2.63(1.87 \text { to } 3.70)^{\star \star \star}$ \\
\hline Pour alcohol & 41.3 & 70.1 & $2.76(2.15 \text { to } 3.55)^{\star \star \star}$ & 13.3 & 24.8 & $3.03(2.14 \text { to } 4.28)^{\star \star \star}$ \\
\hline \multicolumn{7}{|l|}{ Parental actions } \\
\hline Encouraged drinking & 45.6 & 75.2 & $2.52(1.71 \text { to } 3.72)^{\star \star \star}$ & 14.9 & 28.3 & $2.97(1.78 \text { to } 4.96)^{\star \star \star}$ \\
\hline \multirow[t]{2}{*}{ Trained drinking capacity } & 45.4 & 89.1 & $6.20(3.45 \text { to } 11.15)^{\star \star \star}$ & 13.9 & 46.2 & $8.20(4.04 \text { to } 16.64)^{\star \star \star}$ \\
\hline & \multicolumn{3}{|c|}{ Ever drinking } & \multicolumn{3}{|c|}{ Monthly drinking } \\
\hline Number of PPDPsł & \multicolumn{2}{|c|}{ Prevalence (\%) } & AOR (95\% Cl) & \multicolumn{2}{|c|}{ Prevalence (\%) } & AOR (95\% Cl) \\
\hline 0 & \multicolumn{2}{|l|}{32.3} & 1 & \multicolumn{2}{|l|}{10.6} & 1 \\
\hline $1-2$ & \multicolumn{2}{|l|}{45.6} & $1.57(1.21 \text { to } 2.05)^{\star \star \star}$ & \multicolumn{2}{|l|}{13.6} & $1.20(0.79$ to 1.82$)$ \\
\hline $3-4$ & \multicolumn{2}{|l|}{62.1} & $2.85(2.06 \text { to } 3.95)^{\star \star \star}$ & \multicolumn{2}{|l|}{19.8} & $2.57(1.60 \text { to } 4.13)^{\star \star \star}$ \\
\hline 5 or above & \multicolumn{2}{|l|}{78.7} & $5.61(3.66 \text { to } 8.58)^{\star \star \star}$ & \multicolumn{2}{|l|}{32.9} & $6.22(3.59 \text { to } 9.78)^{\star \star \star}$ \\
\hline$p$ for trend & \multicolumn{2}{|l|}{$<0.001$} & & \multicolumn{2}{|l|}{$<0.001$} & \\
\hline
\end{tabular}


Table 2 Associations of PPDP and drinking intention among adolescents

\begin{tabular}{|c|c|c|c|}
\hline & PPDP absent (\%) & PPDP present (\%) & AOR $(95 \% \mathrm{Cl}) \dagger$ \\
\hline \multicolumn{4}{|l|}{ Parents were seen } \\
\hline Drinking & 33.4 & 48.3 & $1.40(1.14 \text { to } 1.72)^{\star \star \star}$ \\
\hline Drunk & 36.8 & 55.9 & $1.57(1.21 \text { to } 2.04)^{\star \star}$ \\
\hline \multicolumn{4}{|l|}{ Parents were heard mentioning } \\
\hline Benefits of drinking & 38.4 & 62.4 & $2.21(1.99 \text { to } 2.44)^{* * *}$ \\
\hline Alcohol tastes good & 35.5 & 58.9 & $1.76(1.39 \text { to } 2.22)^{\star \star \star}$ \\
\hline \multicolumn{4}{|l|}{ Parents being helped } \\
\hline Buy alcohol & 36.8 & 56.6 & $1.81(1.60 \text { to } 2.05)^{\star \star}$ \\
\hline Open bottle & 34.9 & 59.5 & $2.02(1.64 \text { to } 2.48)^{\star * *}$ \\
\hline Pour alcohol & 34.2 & 62.4 & $2.15(1.58 \text { to } 2.93)^{\star \star \star}$ \\
\hline \multicolumn{4}{|l|}{ Parental actions } \\
\hline Encouraged drinking & 37.7 & 71.5 & $3.19(2.28 \text { to } 4.47)^{\star * *}$ \\
\hline Trained drinking capacity & 38.1 & 80.4 & $5.02(1.50 \text { to } 16.7)^{\star * *}$ \\
\hline Number of PPDPs & Prevalence (\%) & & AOR $(95 \% \mathrm{Cl})$ \\
\hline 0 & 28.2 & & 1 \\
\hline $1-2$ & 36.2 & & $1.19(0.97$ to 1.45$)$ \\
\hline $3-4$ & 56.5 & & $2.47(2.06 \text { to } 2.96)^{\star \star \star}$ \\
\hline 5 or above & 73.1 & & $4.32(3.22 \text { to } 5.80)^{\star \star \star}$ \\
\hline$p$ for trend & $<0.001$ & & \\
\hline
\end{tabular}

drinking parents through observation and imitation. ${ }^{25}$ Seeing parents drink or drunk provides direct ways of imitation while other $\operatorname{PPDP}(\mathrm{s})$ may strengthen drinking behaviour through positive reinforcement. For instance, positive parental comments about alcohol, for example, relating to its taste and benefits, may reinforce adolescent drinking behaviour ${ }^{26}$ similar to the effect of parental encouragement of drinking. Supporting these results, parental encouragement of sports and exercise has also increased adolescent involvement in physical activities. $^{27-29}$ Among all the PPDPs, parental training of drinking capacity was most strongly associated with both ever and monthly drinking with AORs of 6.2 and 8.2, respectively. This is consistent with previous findings that verbal persuasion of alcohol drinking can reinforce drinking behaviour through enhancing the valuation of drinking. ${ }^{25-30}$

This study examined various types of PPDPs and adds to the evidence from studies on parental drinking and approval of drinking. ${ }^{19-31}$ Helping parents buy alcohol, opening bottles of alcohol or pouring alcohol was associated with adolescent ever and monthly drinking. These results are consistent with recent findings that children who helped adults fetch or pour drinks were more likely to sip alcohol (AORs 1.97-2.20). ${ }^{20}$ The observed association between PPDPs and adolescent drinking was further supported by the dose-response relation based on the number of PPDPs.

Similar to ever and monthly drinking, adolescent intention to drink was strongly associated with parental training of drinking capacity and encouragement of drinking. This further supported the relation between PPDPs and adolescent drinking. One study showed that positive expectancies towards alcohol in adolescents predicted their intention to drink during adulthood. ${ }^{32}$ Exposure to PPDPs may lead to more positive expectancies towards alcohol drinking and thus enhance drinking intention. It should be noted that the associations of PPDPs with adolescent drinking and intention to drink were independent of parental drinking. While parental drinking is a well-established risk factor for adolescent drinking, our results suggest that to prevent adolescent children from drinking, parents, regardless of their drinking status, should avoid exposing their children to PPDPs.

Uncertain about their prevalence, no time frame was used for PPDPs in the questionnaire so that current and past exposures could be covered. Given the generally stronger associations for monthly drinking than ever drinking, our PPDP items probably reflected more about recent exposures. Moreover, practices in the distant past are unlikely to be reported. For more precise measurements, future studies could examine PPDPs using time frames of 12 months or 30 days, which might show stronger associations with current drinking behaviours.

This study has several limitations. First, exposure to PPDPs was reported by the students only without parental input. However, the consistent associations of different PPDPs with drinking behaviours and intention provided indirect support to the validity of the data. Parental surveys often have lower response rates and 
some parents may under-report PPDPs due to social undesirability, whereas students are unlikely to have such concerns in reporting PPDPs. Boys were overrepresented in our sample because two boys' schools were included. However, other sociodemographic characteristics (age, place of birth, perceived family affluence and highest parental education level) were comparable with those of a large representative local secondary school sample $(\mathrm{N}=45857),{ }^{33}$ where Cohen's w ranged from 0.02 to 0.20 , indicating only small differences between the two groups.

\section{CONCLUSION}

Exposure to PPDPs was associated with drinking and intention to drink among Hong Kong Chinese adolescents. More studies, especially prospective studies, should be conducted to confirm these results, followed by interventional studies. If causal, avoiding exposure to PPDPs may help prevent adolescents from drinking.

Acknowledgements The authors thank the Health Care and Promotion Fund for funding support, and schools and students for participation in the survey.

Contributors SYH, MPW, WSL, SPPT, RH and THL designed the study and wrote the protocol. WMA analysed the data and wrote the first draft of the manuscript. All the authors contributed to and have approved the final manuscript.

Funding This study was supported by the Health Care and Promotion Fund, \#25110534.

\section{Competing interests None declared.}

Ethics approval The study protocol was approved by the Institutional Review Board of the University of Hong Kong/Hospital Authority Hong Kong West Cluster (UW12-421). The survey was conducted in accordance with the approved guidelines.

Provenance and peer review Not commissioned; externally peer reviewed.

Data sharing statement No additional data are available.

Open Access This is an Open Access article distributed in accordance with the Creative Commons Attribution Non Commercial (CC BY-NC 4.0) license, which permits others to distribute, remix, adapt, build upon this work noncommercially, and license their derivative works on different terms, provided the original work is properly cited and the use is non-commercial. See: http:// creativecommons.org/licenses/by-nc/4.0/

\section{REFERENCES}

1. Hingson RW, Zha W, Weitzman ER. Magnitude of and trends in alcohol-related mortality and morbidity among US college students ages 18-24, 1998-2005. J Stud Alcohol Drugs 2009;16:12-20.

2. Brown SA, Tapert SF, Granholm E, et al. Neurocognitive functioning of adolescents: effects of protracted alcohol use. Alcohol Clin Exp Res 2000;24:164-71.

3. World Health Organization. Global Status Report on Alcohol and Health. Secondary Global Status Report on Alcohol and Health. 2014. http://www.who.int/substance_abuse/publications/global_ alcohol_report/en/

4. Centers for Disease Control and Prevention. Youth Risk Behavior Surveillance-United States. Secondary Youth Risk Behavior Surveillance-United States. 2014. http://www.cdc.gov/mmwr/ preview/mmwrhtml/ss6304a1.htm

5. van der Vorst $\mathrm{H}$, Engels RC, Meeus W, et al. The role of alcohol-specific socialization in adolescents' drinking behaviour. Addiction 2005;100:1464-76.

6. Van Der Vorst H, Engels RCME, Deković M, et al. Alcohol-specific rules, personality and adolescents' alcohol use: a longitudinal person-environment study. Addiction 2007;102:1064-75.
7. Spijkerman R, van den Eijnden RJ, Huiberts A. Socioeconomic differences in alcohol-specific parenting practices and adolescents' drinking patterns. Eur Addict Res 2008;14:26-37.

8. Ennett ST, Jackson C, Bowling JM, et al. Parental socialization and children's susceptibility to alcohol use initiation. J Stud Alcohol Drugs 2013;74:694.

9. Alati R, Baker P, Betts KS, et al. The role of parental alcohol use, parental discipline and antisocial behaviour on adolescent drinking trajectories. Drug Alcohol Depend 2014;134:178-84.

10. Yu J. The association between parental alcohol-related behaviors and children's drinking. Drug Alcohol Depend 2003;69:253-62.

11. Jackson C, Henriksen L, Dickinson D. Alcohol-specific socialization, parenting behaviors and alcohol use by children. J Stud Alcohol Drugs 1999;60:362.

12. Wood MD, Read JP, Mitchell RE, et al. Do parents still matter? Parent and peer influences on alcohol involvement among recent high school graduates. Psychol Addict Behav 2004;18:19.

13. White V, Bariola E. Australian secondary school students' use of tobacco, alcohol, and over-the counter and illicit substances in 2011. Secondary Australian secondary school students' use of tobacco, alcohol, and over-the counter and illicit substances in 2011. 2012. http://www.nationaldrugstrategy.gov.au/internet/drugstrategy/ Publishing.nsf/content/BCBF6B2C638E1202CA257ACD0020E35C/ \$File/National\%20Report_FINAL_ASSAD_7.12.pdf

14. Donovan JE. Really underage drinkers: the epidemiology of children's alcohol use in the United States. Prev Sci 2007;8:192-205.

15. Kelly A, Chan GC, O'Flaherty M. How important is the context of an adolescent's first alcoholic drink? Evidence that parental provision may reduce later heavy episodic drinking. Eur Addict Res 2012;18:140-8.

16. Komro KA, Maldonado-Molina MM, Tobler AL, et al. Effects of home access and availability of alcohol on young adolescents' alcohol use. Addiction 2007;102:1597-608.

17. Kaynak Ö, Winters KC, Cacciola J, et al. Providing alcohol for underage youth: what messages should we be sending parents? J Stud Alcohol Drugs 2014;75:590-605.

18. Gilligan C, Kypri K, Johnson N, et al. Parental supply of alcohol and adolescent risky drinking. Drug Alcohol Rev 2012;31:754-62.

19. Foley KL, Altman D, Durant RH, et al. Adults' approval and adolescents' alcohol use. J Adolesc Health 2004;35:345.e17-26.

20. Jackson C, Ennett ST, Dickinson DM, et al. Attributes that differentiate children who sip alcohol from abstinent peers. $J$ Youth Adolesc 2013;42:1687-95.

21. Au WM, Ho SY, Wang MP, et al. Alcohol drinking and pro-drinking practices in parents of Hong Kong adolescents. Alcohol Alcohol 2014;49:668-74.

22. Au WM, Ho SY, Wang MP, et al. Correlates of pro-drinking practices in drinking parents of adolescents in Hong Kong. PLOS ONE 2015;10:e0119554.

23. Li R, Wong P. The 2011/12 survey of drug use among students. Hong Kong: Narcotics Division, Security Bureau, 2013.

24. Hong Kong Economic and Trade Office. A wine trading and distribution hub in Asia. Secondary A wine trading and distribution hub in Asia. 2013. http://www.hketousa.gov.hk/usa/wine/ HKidealplace.html

25. Bandura A. Social Learning Theory. New York: General Learning Press, 1971.

26. Akers RL, Krohn MD, Lanza-Kaduce L, et al. Social learning and deviant behavior: A specific test of a general theory. Am Sociol Rev 1979;44:636-55.

27. Anderssen N, Wold B. Parental and peer influences on leisure-time physical activity in young adolescents. Res $Q$ Exerc Sport 1992;63:341-8.

28. Snyder EE, Spreitzer EA. Correlates of sport participation among adolescent girls. Res Q 1976;47:804-9.

29. Snyder EE, Spreitzer EA. Family influence and involvement in sports. Res Q 1973;44:249-55.

30. Andrews JA, Hops H, Ary D, et al. Parental influence on early adolescent substance use specific and nonspecific effects. $J$ Early Adolesc 1993;13:285-310.

31. Donovan JE. Adolescent alcohol initiation: a review of psychosocial risk factors. J Adolesc Health 2004;35:529.e7-18.

32. Zamboanga BL, Ham LS, Van Tyne K, et al. Alcohol expectancies among adolescent nondrinkers: they may not be drinking now, but they're 'thinking about it'. J Adolesc Health 2011;49:105-7.

33. Census and Statistics Department. Hong Kong Annual Digest of Statistics. Secondary Hong Kong Annual Digest of Statistics. 2013. https://www.censtatd.gov.hk/hkstat/sub/sp140.jsp? productCode $=\mathrm{B} 1010003$ 